\title{
Correction notice to: Tongue dysfunction screening: assessment protocol for prescribers
}

\author{
J Dentofacial Anom Orthod 2015;18:408 \\ https://doi.org/10.1051/odfen/2015026
}

\author{
H. Gil ${ }^{1}$, N. Fougeront ${ }^{2}$ \\ 1 Maxillofacial physiotherapist \\ 2 Dental surgeon, Orofacial Functional Disorder Consultation, Odontology Dept, Charles-Foix \\ Hospital, Ivry-sur-Seine, France
}

Note to the reader: Linguistic errors were introduced in the initial version of this article. The new version contains all the corrections.

Address for correspondence:

Hélène Gil

22, Rue de Turin 75008 Paris, France

E-mail: h70gil@orange.fr

Article received: 04-06-2018. Accepted for publication: 04-06-2018.

This is an Open Access article distributed under the terms of the Creative Commons Attribution License (http://creativecommons.org/licenses/by/4.0), which permits unrestricted use, distribution, and reproduction in any medium, provided the original work is properly cited. 